\title{
A luz - elemento primordial no Teatro de Sombras
}

The light - primordial element in Shadow Theater

Fabiana Lazzari de Oliveira ${ }^{1}$ Valmor (Nini) Beltrame ${ }^{2}$ 


\section{Resumo}

O presente artigo reflete sobre a luz como elemento técnico e expressivo no Teatro de Sombras e discorre sobre esse recurso nas suas expressões tradicionais e diferentes utilização por grupos de teatro de sombras contemporâneos; aponta para a variedade e diferenças nos tipos de lâmpadas, focos luminosos e suas possibilidades expressivas para a prática dessa arte na atualidade. Para isso, recorre-se a contribuições de pesquisadores, artistas brasileiros e estrangeiros, evidenciando a importância da luz nas suas atividades criadoras.

Palavras-chave: Teatro de Sombras; luz; lâmpadas; foco luminoso.

\section{Abstract}

This article studies light as a technical and expressive element in shadow theater, discussing this resource in its traditional expressions and in different usages by contemporary shadow theater groups. The essay enfasizes the variety and different types of lamps, light focus and their expressive possibilities for the current practice of this art. For such a purpose, we analyse the contribution of both Brazilian and foreign artists and researchers, bringing forth the importance of light in their creative activities.

Keywords: Shadow theater; light; lamps; light focus.
ISSN: 1414.5731

E-ISSN: 2358.6958 
O Teatro de Sombras ${ }^{3}$ é uma arte cuja realização envolve o uso de fontes de luz, superfície, tela ou outro suporte para a projeção de imagens, corpos (objetos, silhuetas recortadas, corpo humano, bonecos) e o trabalho ator. A sombra proveniente de um corpo que se move, projetada em superfícies e suas combinações trabalhadas pelo ator, formam a linguagem básica desta manifestação conhecida como Teatro de Sombras ou Magia Luminosa.

Por suas características, o Teatro de Sombras é uma linguagem que suscita outros significados que não os do cotidiano. Isso se deve às possibilidades de insinuar sem deixar ver, de deformar a realidade e incrementá-la, de utilizar recursos característicos que em outros meios seria muito difícil conseguir. Essa linguagem é muito antiga e, de acordo com a sua história, ela vai se modificando com o passar do tempo, as pesquisas vão se aprofundando e incorporando as descobertas técnicas e evoluções da iluminação.

O que caracteriza a maioria dos espetáculos teatrais produzidos hoje é o afastamento da estética realista-naturalista. De fato, a reprodução da realidade já não estimula os artistas que fazem Teatro de Sombras. Interessa-lhes a recriação do real e, por isso, se percebe o predomínio de três modalidades nos processos criativos: a sombra de silhuetas recortadas em diversos tipos de materiais; a sombra obtida com objetos tridimensionais; e as sombras corporais. É comum os grupos misturarem propositalmente essas modalidades (Beltrame, 2012, p.9).

A tarefa de mapear os tipos de lâmpadas utilizadas nesses espetáculos é quase impossível considerando a diversidade de produtos disponíveis no mercado. Somase a isso a engenhosidade de grupos que, nas suas experimentações, inventam e adaptam lâmpadas e reutilizam materiais para a produção da luz em seus espetáculos. Este estudo propõe fazer uma compilação de diferentes tipos de lâmpadas e fontes de luz utilizadas nessa arte. Antes, porém, é interessante perceber a importância da luz nas expressões tradicionais do teatro de sombras.

\section{A luz no Teatro de Sombras Tradicional}

Hoje, a expressão Teatro de Sombras é a denominação mais comum para designar essa arte, mas, ela já foi conhecida no Brasil como Sombras Chinesas, o que se deve basicamente à crença de que esta arte nasceu na China. No entanto, ela obteve outras denominações em sua história e chama a atenção o quanto o uso da luz está relacionado com suas designações.

A expressão Magia Luminosa foi usada pela primeira vez, segundo Carlos Angoloti (1990, p.88), por Jac Remise, que situa a origem do Teatro de Sombras e, mais concretamente da lanterna mágica, nas práticas necromânticas da Europa do século

\footnotetext{
3 Parte deste artigo contém estudos e considerações extraídos da Dissertação "Alumbramentos de um corpo em Sombras - 0 ator no Teatro Lumbra de Animação" de Fabiana Lazzari de Oliveira apresentados no PPGT - UDESC em 2011.
} 
XVI. Mediante jogos de luzes, espelhos e fumaça faziam surgir imagens terríveis, representações demoníacas ou espíritos dos mortos. A pesquisadora chinesa Érica Luo (2012, p. 94) escreve que durante a Dinastia Song (960-1279 d.C.) foram encontrados os primeiros registros, em forma escrita, das apresentações do Teatro de Sombras, também conhecido como "jogo de luzes" ou "guerra das sombras", remontando a mais de mil anos. São expressões que já evidenciavam a importância do elemento "luz" para a realização dessa arte.

Nas formas de expressão tradicional do Teatro de Sombras em países como Indonésia (Ilha de Java), China, Índia, Tailândia, Sri Lanka, predominava, historicamente, o uso da lamparina à base de azeite de coco ou outros vegetais. Estudos de Jô Humphrey (1986) detectam um crescente abandono desse recurso em substituição a lâmpadas comuns, industrializadas.

A escolha adequada da fonte luminosa para o espetáculo é a que melhor se ajusta às características e necessidades do trabalho (sombras corporais, sombras com silhuetas recortadas em cartão ou couro, sombra de objetos, ou a mistura de todos esses materiais) sendo coerente com o projeto inicial proposto para a cena. Michael Meschke (1985, p. 87) exemplifica em seu livro Una Estética para El Teatro de Títeres:

Ainda que o Dalang, ator-animador de sombras ${ }^{4}$ indonésias, disponha da luz elétrica, conserva a lâmpada de azeite porque responde melhor à necessidade de magia do teatro de Wayang-Kulit, teatro dos tempos remotos da humanidade quando a vida e a morte, a realidade e a ilusão, o homem e o espírito, os deuses e os demônios, viviam numa luz vacilante e incerta 5 .

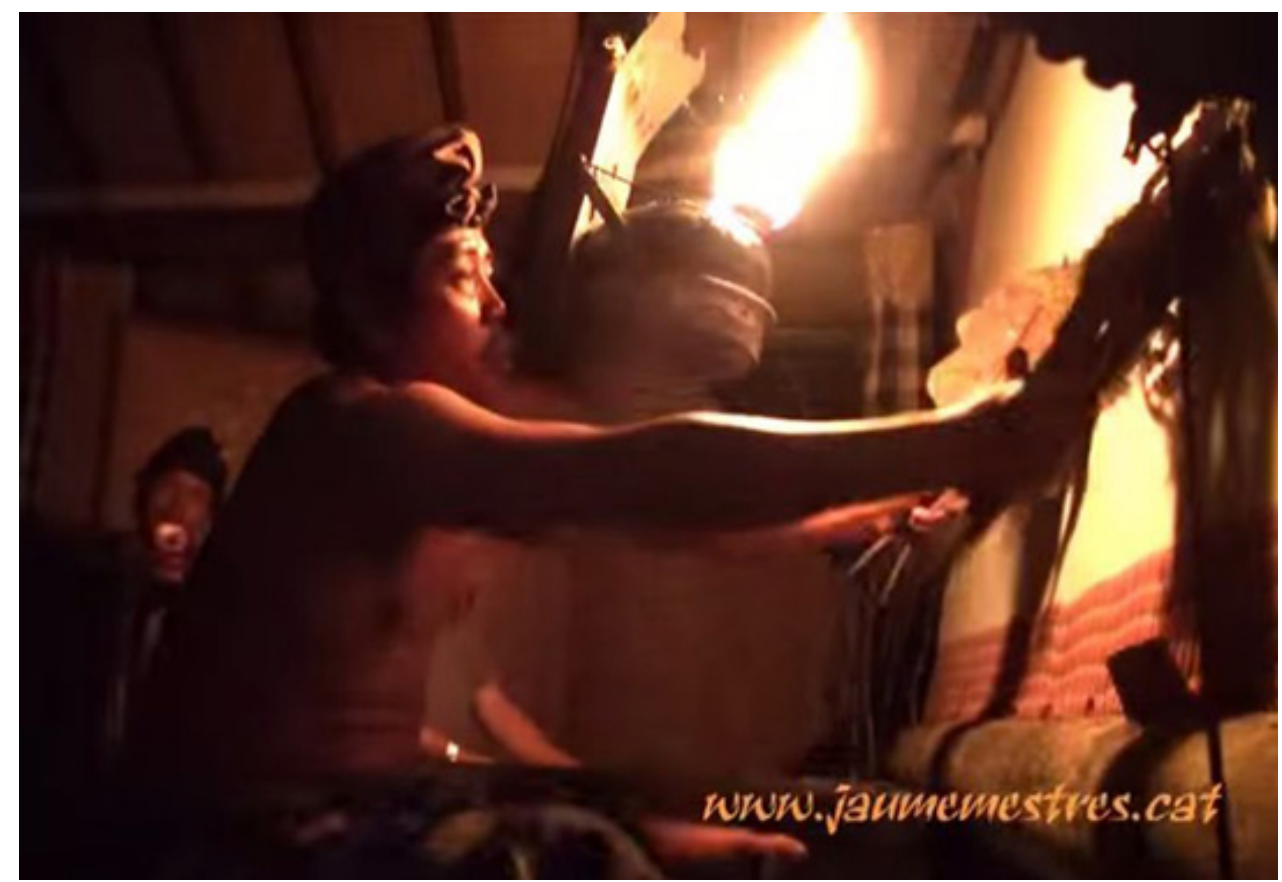

Figura 1 - Wayang Kulit que conserva a lâmpada de azeite em suas apresentações - PrintScreen da apresentação do espetáculo in: YouTube www_youtube_com_watch_v=CRdWhZJUGkA

4 Na tradução para o português corrigimos a citação de Meschke, pois de acordo com os estudiosos de Teatro de Sombras, o Dalang é o ator-animador de Sombras Javanesas e não Chinesas.

5 Aunque el dalang, actor/titiritero de sombras chinescas indonésio, dispone de luz eléctrica, conserva la lámpara de aceite porque responde mejor a nece- sidad de magia del teatro de wauang-kulit, ese teatro de los tiempos remotos de la humanidad cuando la vida y la muerte, la realidad y la ilusión, el hombre y el espíritu, los dioses y los demonios, vivían a una luz vacilante e incierta (Meschke,1985, p. 87, tradução nossa). 
Contrariando a afirmação de Meschke, Jô Humphrey6 (1986, p. 73-91) relata que, conforme sua experiência, de pesquisar e de praticar teatro chinês atualmente utiliza, sim, a luz fluorescente: "nós usamos um tubo fluorescente porque difunde os raios da luz, criando menos sombras provenientes das varas e das mãos dos performers". Destaca-se que o uso desse tipo de recurso como a lâmpada fria, o tubo fluorescente, ou até outra escolha efetuada pela encenação, pode agregar elementos e perder outros. No caso específico dessa lâmpada fluorescente (exemplo na figura 2), ela colabora para a ocultação da sombra das varas de manipulação das silhuetas, no entanto, impede a exploração de recursos que possibilitam a deformação das imagens, impedindo, por exemplo, os movimentos de ampliação e diminuição das mesmas. Isso ocorre porque ao afastar a silhueta da tela, sua imagem desaparece; diferentemente do que ocorre com lâmpadas halógenas que, dependendo de como são utilizadas, projetam a sombra "deformada" da silhueta na tela.

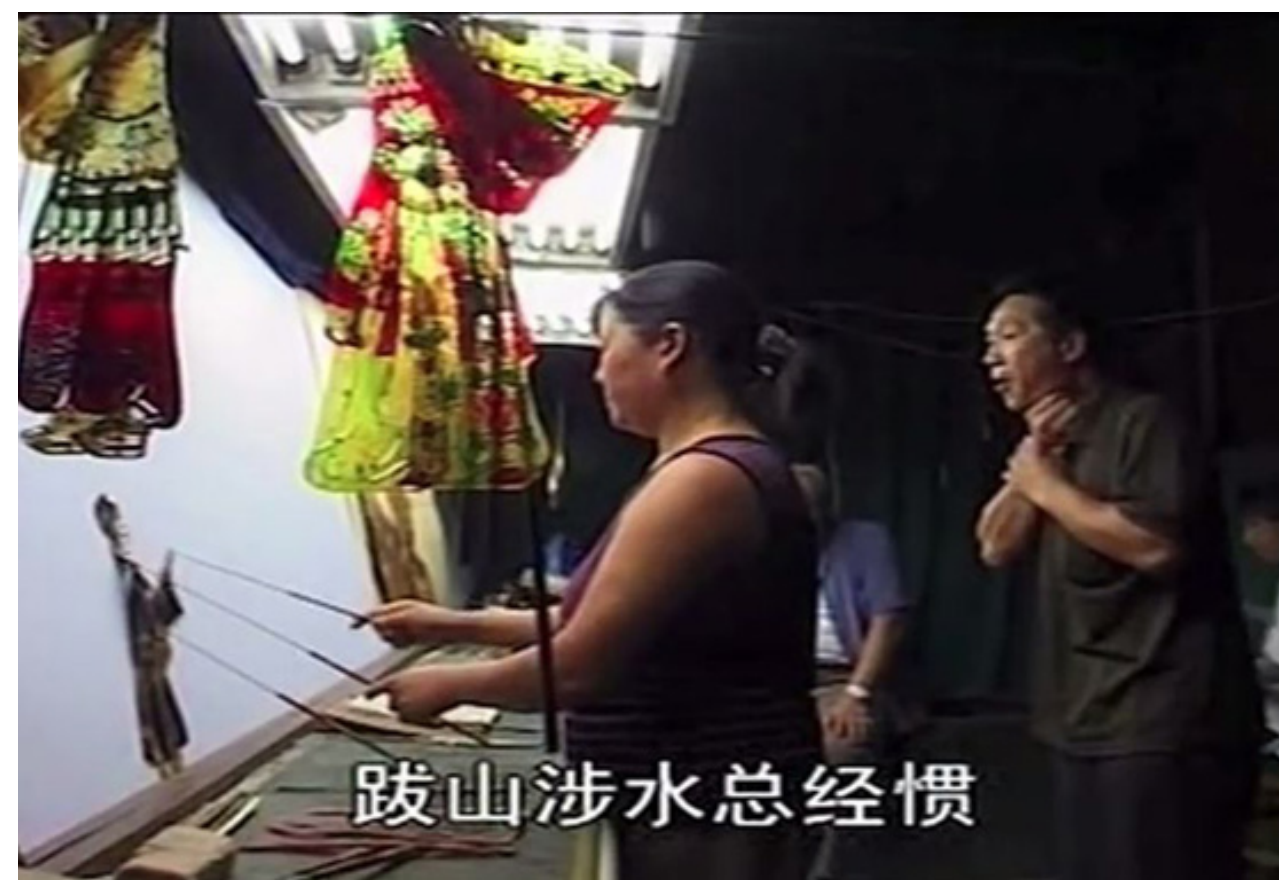

Figura 2 - Lâmpadas florescentes utilizadas no Teatro de Sombras Chinês - PrintScreen da reportagem Chinese shadow theatre - backstage In: YouTube - www_youtube_com_watch_v=dmqNXIY4j74

Roger Long (1986, p. 93-106), outro pesquisador da área, fala da modernização do teatro javanês, reafirmando a mudança da tradicional lâmpada de óleo para a lâmpada elétrica e a sua subsequente evolução. Ele ainda relata outras mudanças decorrentes dessa modernização no teatro javanês:

o uso do microfone e amplificador eletrônico; as transmissões de rádio e televisão e os seus efeitos na performance, e, talvez o mais importante, a aquisição massificada de toca-fitas e o seu impacto sócio-econômico no wayang resultantes do seu uso. (Long, p. 93).

6 Jô Humphrey é responsável pelo Teatro de Sombras Yueh Lung que concentra sua pesquisa na tradição do Teatro de Sombras chinês, conhecido como a Tradição Luanchou. Até o começo do século XX, este era um dos mais populares entretenimentos na China. 
Menciona também outros resultados das mudanças na confecção, pintura e atuação no wayang que vieram acompanhadas do turismo e do comércio crescente com países estrangeiros. É importante perceber que o texto de Long é de 1986, portanto, hoje em dia, o uso de tecnologias recentes é preponderante. A crescente ocidentalização que vem acontecendo em certas regiões da Indonésia, sem dúvida, modifica o modo de apresentação das manifestações do seu teatro de sombras tradicional, o Wayang Kulit. Saber se isso constitui descaracterização ou atualização dessa arte é tema para outro estudo. Importante é perceber que no centro dessas mudanças a luz tem sido um dos seus aspectos centrais.

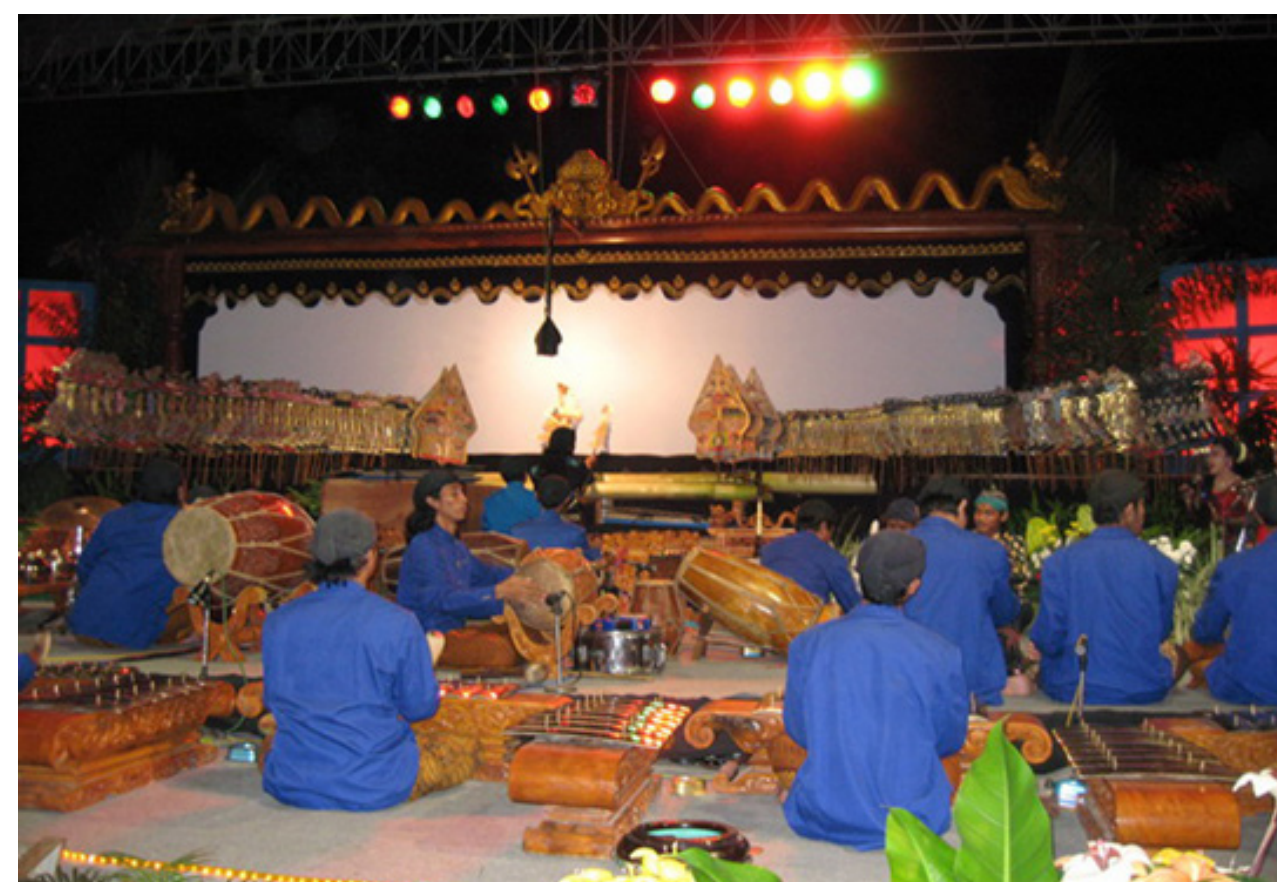

Figura 3 - Pagelaran Wayang Kulit - foto retirada do site: http://ensiklopediaindonesia.com/seni-dan-budaya-indonesia/pagelaran-seni-wayang-kulit-kesenian-tertua-di-indonesia/

A estrutura do espetáculo de Teatro de Sombras tem se modificado ultimamente. Virtualmente, as inovações tecnológicas previamente discutidas por Long (1986, p. 93-106) têm afetado em algum aspecto a qualidade ou natureza da performance no wayang:

Luzes, microfones, e inovações nas transmissões são todos avanços tecnicamente mundanos que nos entusiasmam pouco - mesmo no contexto e impacto nas formas das artes tradicionais. Afinal, a luz elétrica certamente afetou o que nós agora consideramos como sendo "tradicional" o estilo de drama europeu do século XIX e nós não ficamos sentados reclamando sobre a perda da "atmosfera" de velas e luzes a gás em nossos teatros.

Long (1986, p. 93-106) conclui afirmativamente sobre o wayang, dizendo que a cada vantagem conquistada através do avanço tecnológico, alguns aspectos são perdidos ou diminuídos, porém, "a tecnologia está mudando o wayang e continuará a fazê-lo. É importante que nós, que o amamos e o estudamos nos mantenhamos flexíveis para as mudanças" (Long, 1986, p.106). A reflexão efetuada por Long ganha 
relevância uma vez que não é possível olhar para as manifestações do teatro tradicional como expressões datadas e presentes em contextos sociais e culturais imutáveis. As transformações tecnológicas e as mudanças econômicas afetam diretamente a produção artística uma vez que ela é manifestação viva e reflete os problemas e expectativas de quem a produz. Isso interfere diretamente no uso dos recursos utilizados no Teatro de Sombras.

\section{Tipos de lâmpadas - qual foco?}

A luz determina novas percepções do espaço: "Sem luz, os olhos não podem observar nem forma, nem cor, nem espaço ou movimento" (Arnheim, 1996, pg. 293). O homem conseguiu que a luz fosse mais perdurável: a lâmpada de azeite e a vela foram substituídas pela lâmpada elétrica, por lâmpadas halógenas e pelas conhecidas LEDs. A sombra, então, se fez mais duradoura e manipulável.

Segundo Roberto Casati (2001, p. 32) "a renovação contemporânea do Teatro de Sombras se deve a um aprimoramento tecnológico que altera a natureza da interpretação". Isso ocasiona mudanças na poética do espetáculo, como por exemplo: a ruptura com o espaço - o ator-animador passa a não se esconder atrás das telas e ampliar seu espaço de trabalho; mudança na criação de silhuetas e de telas - trabalha-se também com a sombra de objetos e do corpo humano, não somente com silhuetas recortadas em couro e cartão como tradicionalmente acontecia. Fabrizio Montecchi (2012, p. 29) explana que ocorre "uma mudança técnica fundamental: a transformação do tradicional espaço das sombras em um dispositivo de projeção", isto é, a sombra nítida que era obtida somente no contato direto com a tela, agora é possível obtê-la quando é projetada. Isso permite que o ator se afaste da tela e atue no espaço, criando outras possibilidades expressivas com a sombra. Deste modo, favorece que o ator torne visíveis os seus movimentos efetuados em cena. Essa transformação do espaço propiciou também que se ampliassem os tipos de tela para a projeção não sendo mais utilizadas somente as de tecido branco, mas tecidos transparentes, coloridos e diferentes tipos de papel. Nessa perspectiva a tela se abre para o uso de outras superfícies como paredes, muros de concreto de diferentes tamanhos, formas e cores. Consequentemente, isso diminui a exploração de movimentos que se pode obter com as telas de tecido, no entanto, criam-se possibilidades expressivas que se distanciam das práticas tradicionais do Teatro de Sombras.

Domingo Castillo (2005, p. 67) afirma que é inquestionável a grande influência que a fonte de luz exerce na poética expressiva da sombra. É importante evidenciar que o acúmulo de efeitos luminotécnicos buscando espetacularidade causa impactos momentâneos aos espectadores, mas pode confundir seus sentidos. As sombras, para Castillo (2005, p. 67) são a linguagem das emoções e da sugestão. Por isso se busca a dosagem adequada dos meios expressivos para poder produzir os efeitos desejados. Talvez seja necessário ter-se em conta que, ao apropriar-se de um amplo universo de recursos expressivos, pode-se paradoxalmente criar um vazio de sentidos. Nessa direção, a incorporação de novos recursos para a cena ganha relevância se estiver acompanhada de perguntas como: que teatro se pretende realizar? para que servem tais recursos visuais? como as imagens colaboram para a efetivação do 
teatro que se pretende mostrar?

Quando se fala em lâmpadas no teatro, imediatamente aparece a palavra "iluminação". Patrice Pavis (1999: 201) declara que o termo iluminação "vem sendo substituído, cada vez mais, na prática atual, pelo termo luz, provavelmente para indicar que o trabalho da iluminação não é iluminar um espaço escuro, mas sim criar a partir da luz". Nos dias de hoje, já temos algumas pesquisas sobre a atuação da luz relatando e analisando a sua performatividade na cena: "a função da luz se transforma e assume novas características e encargos, a visibilidade da cena ganha espaço e, a recepção se converte em parte constitutiva desta cena, incumbindo a luz de um papel primordial" (Luciani, 2012, p. 88). Sendo o Teatro de Sombras um "jogo de luzes" a luz é um dos elementos fundamentais dessa arte e é na criação do espaço produzido por essa luz que acontece a atuação que gera a sombra artística, projetada.

De acordo com Ernesto Bechara (apud Marina, 2012, p.11) "A luz tem um lado estético e um lado funcional. E as funcionalidades marcam as necessidades lumínicas de uma obra. [...] A sombra é usada como recurso para shows e tantas outras obras." Percebe-se que pensar a sombra é tão fundamental quanto pensar a luz como ferramentas dramáticas, embora em shows a sombra seja mais comumente utilizada como recurso ilustrativo.

No Teatro de Sombras contemporâneo, um fato decisivo na busca de novas possibilidades expressivas tem sido a experimentação do terreno das lâmpadas halógenas. A descoberta dessa lâmpada que possui luz branca e brilhante, que transmite luz puntiforme e possibilita realçar as cores e os objetos com eficiência energética maior do que a das lâmpadas comuns trouxe muitas transformações no Teatro de Sombras. Elas aumentaram as possibilidades de escolhas estéticas já que a silhueta/ objeto/corpo não necessita mais estar perto da tela para ter nitidez, a lâmpada pode estar em qualquer lugar do espaço e continuará oferecendo uma boa definição7. Na atualidade, escolhe-se a lâmpada de acordo com a qualidade que se quer dar à sombra (nítida ou difusa) e essa, por sua vez, depende da qualidade da lâmpada em relação à intensidade, potência e a quantidade de filamentos.

O Teatro de Sombras utiliza-se da tecnologia adaptando-a às suas necessidades. A escolha de diferentes tipos de lâmpada e as combinações entre eles determinam: o tipo de manipulação, o tamanho da tela, a opção de dividi-la em zonas de uso independente. Ademais, determinam também as características da sombra obtida como, por exemplo: contorno nítido ou difuso; variação do tamanho com pouca movimentação da silhueta; a multiplicidade das imagens; o aumento de suas possibilidades de transformação e de deformações. Pode-se trabalhar com objetos que tenham rotação em seu próprio eixo interno, como com um boneco ou uma máscara três faces, dando à silhueta uma qualidade tridimensional, não utilizando somente siIhuetas planas ou chapadas. Conforme Rainer Rausch "a sombra projetada parece ter profundidade espacial, a perspectiva se movimenta"8 e o ator-animador, enquanto

7 Antes da descoberta da lâmpada elétrica e consecutivamente a halógena, as silhuetas precisavam ficar o mais próximo da tela, pois quanto mais afastada menos definição ela tinha.
8 "The shadow which is cast purports to have spatial depth and the perspective moves." (Reusch, Rainer. In: http://www.schattentheater.de/files/englisch/geschichte/geschichte.php - tradução nossa). 
segura com uma das mãos a silhueta distante da tela, com a outra pode, sem problemas, controlar a lâmpada e criar formas diferentes para a sombra. Tradicionalmente, o que proporcionava movimentos às silhuetas eram as suas articulações e a manipulação conferida pelo ator-animador. Porém, hoje, nas práticas mais contemporâneas, a luz se tornou uma ferramenta de grande valor nas experimentações de grupos. 0 movimento selecionado e planejado do foco luminoso possibilita criar impressão de vida à silhueta. Ou seja, surgiram novas possibilidades de manipulação para a projeção da sombra.

Para escolher o tipo de lâmpada são considerados alguns fatores, entre eles a sua potência, a intensidade do feixe de luz e a possibilidade de regulação que influenciará na distância de projeção. Algumas questões merecem observação: A) a abertura do feixe de luz - quanto mais concentrado, mais produz sombras com contorno nítido, obtidas com as lâmpadas halógenas e lâmpadas puntiformes; quando a abertura do feixe de luz é maior, produz sombras com contorno difuso obtidas com lâmpadas de filamento, lâmpadas comuns, tubos fluorescentes, lâmpada de tubo de néon, de iodo e velas (vide figura 5); B) a possibilidade de controlar o feixe de luz para delimitar a zona iluminada; para isso se utilizam projetores e focos; C) a distância necessária entre a fonte de luz e a tela; D) a situação da luz com respeito à tela em função da altura do ângulo de inclinação; E) a possibilidade de colorir a luz, mediante filtros e gelatinas coloridas transparentes; etc. (Castilho, 2004, p. 65). Segundo Fávero (apud Oliveira, 2011, p. 48) "pode-se fazer a dramaturgia por contraste, por similaridade, por volume, por cor, por intensidade, por velocidade, por ritmo", isto é, pode-se dizer que a luz é parte determinante da dramaturgia no Teatro de Sombras, tornando-a assim um elemento primordial nessa arte.

Quanto à abertura do feixe de luz, por exemplo, percebe-se na figura 4 que o aspecto da sombra "C2", projetada pelo elemento "c" com a lâmpada puntiforme de um projetor, oferece uma notável definição (o preto da sombra e o branco da luz estão quase em oposição direta, se observa um fino traço cinza: a sombra é nítida), o que é diferente do caso da sombra "C1", projetada pelo mesmo objeto "c" com luz de uma lâmpada normal de filamento grosso na qual não se consegue determinar os pontos exatos do começo e do fim (observa-se um amplo traço acinzentado, contorno difuso: a sombra é desfocada) (Piazza e Montecchi, 1987, p. 86).

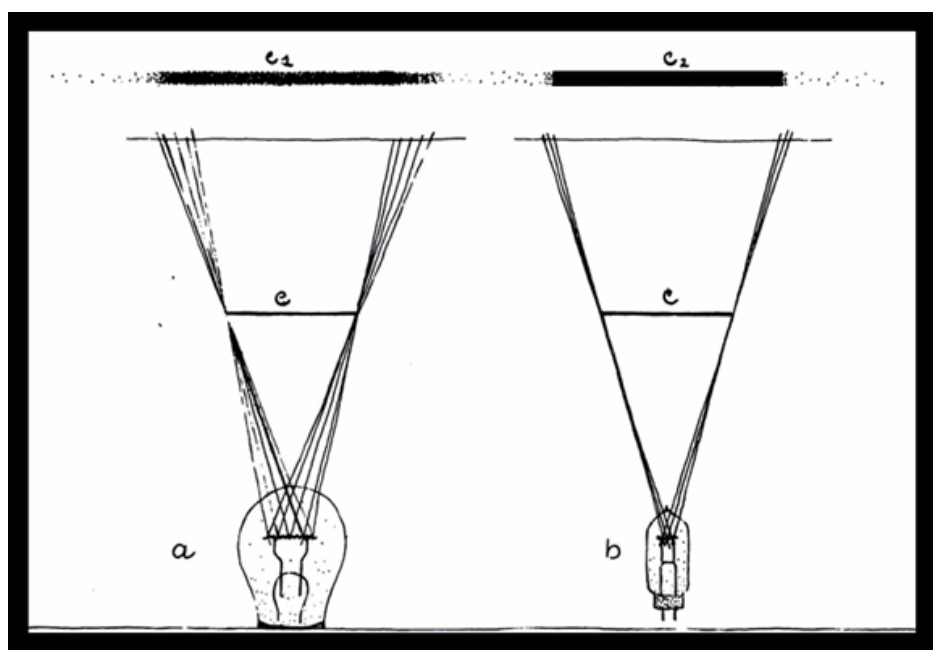

Figura 4 - Fontes Luminosas (Piazza e Montecchio, 1987, p. 86). 


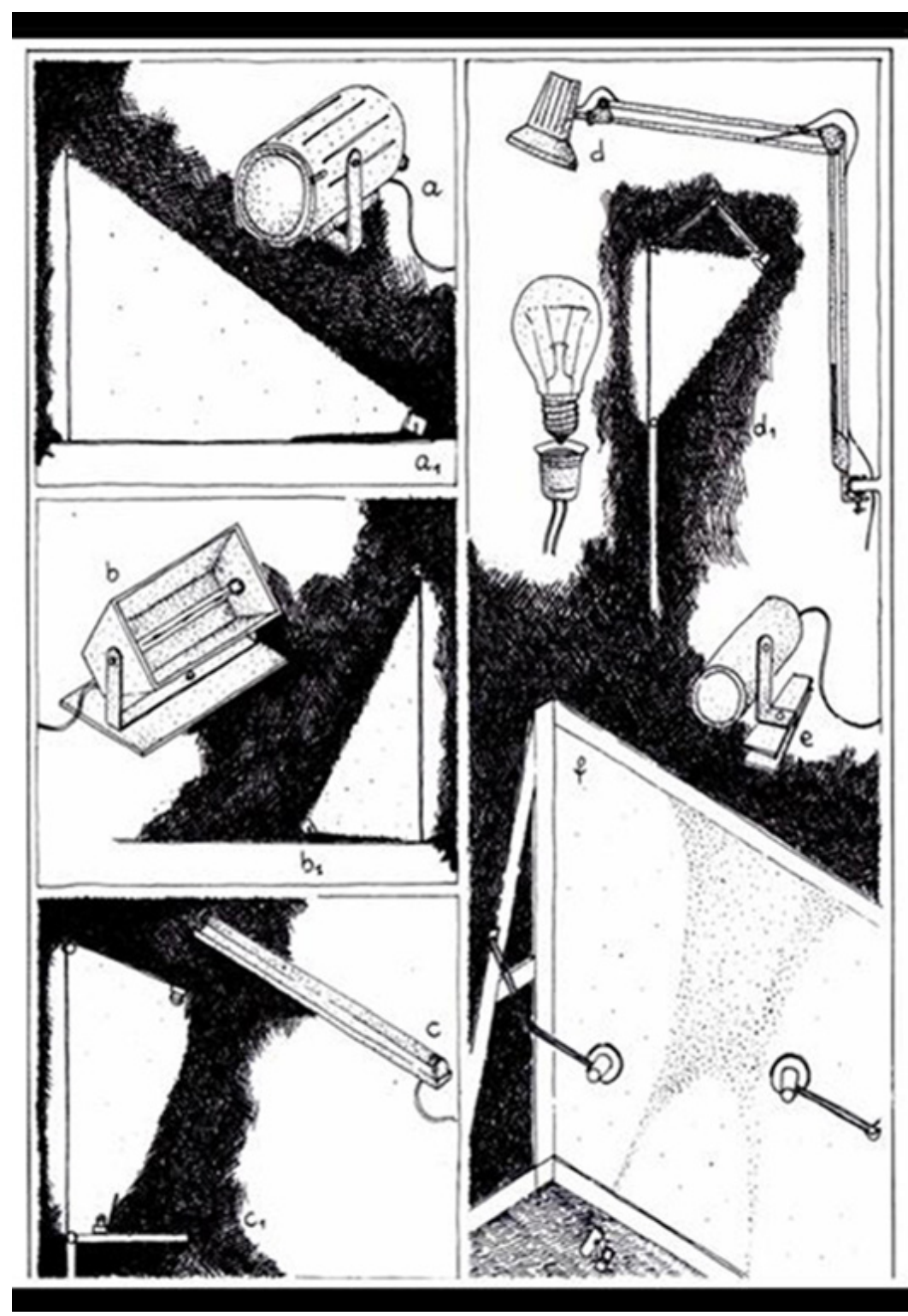

Figura 5 - Exemplos de lâmpadas de filamento: as halógenas no refletor (a), lâmpada de tubo de néon (b), de iodo (c) e lâmpadas comuns com braço extensivo (d) e foco (e). Também, na figura 5, desenhos do possível espaço que a luz da lâmpada abrange (a1, b1, c1, d1, f) (Piazza e Montecchi, 1987, p. 87).

Como exemplos de elementos mais utilizados hoje, temos os focos de teatro com refletor e lâmpadas halógenas, que produzem sombras com perfil nítido; ou episcópicas, que produzem sombras com perfil difuso; focos confeccionados manualmente, com lâmpadas halógenas de gás concentrado e potências que oscilam entre 50 a 100 watts conectadas a 12 volts ou, de 125 e 250 watts conectadas a 24 volts, que produzem sombras com perfis nítidos e permitem, ao aproximá-los à silhueta, variar o tamanho da imagem/sombra consideravelmente ou realizar enquadramentos diferentes da silhueta/objeto/corpo. Pode-se usar também lâmpada portátil permitindo projetar e deslizar a sombra por qualquer ponto da tela.

Outros recursos frequentemente utilizados são os projetores de dispositiva com lentes. A variedade de lentes permite jogar com a distância focal - uma lente angular de $55 \mathrm{~mm}$ proporciona uma imagem projetada maior que uma lente normal de 85 $\mathrm{mm}$ mantendo-se a mesma distância entre o projetor e a tela. Esses projetores po- 
dem funcionar com lâmpada branca sem deixar marca do filamento na tela.

Os retroprojetores permitem projetar cenografias recortadas em cartão, apoiando-as diretamente sobre a superfície de cristal; possibilitam projetar fundos cenográficos fixos desenhados em lâmina de acetato e manipular silhuetas diretamente sobre o retroprojetor. Todavia, adverte-se que os movimentos devem ser suaves para evitar a produção de imagem difusa da sombra na tela. Projetores de vídeo, flash estroboscópio e mesmo diversos tipos de lanternas são frequentemente usados.

Como se percebe, as possibilidades do uso da luz produzida por diferentes tipos de lâmpadas ou fontes luminosas são bem diversas. Experimentando, descobre-se a importância da luz para criar a poética do espetáculo e ilusão cênica. O raio da luz pode criar várias mudanças de acordo com a movimentação que o ator faz com o foco e de sua posição no espaço teatral: de baixo, de cima, da esquerda, da direita, lâmpada móvel, lâmpada fixa, lâmpada colorida, etc. A luz ainda mostra imagens diferentes em superfícies planas ou arredondadas, em telas côncavas ou convexas. Determina formas e cores. Assim como, a lâmpada em diferentes distâncias e intensidades produz efeitos diversos.

Em função da grande variedade de características da movimentação que o ator pode fazer com o foco de luz no espaço, é possível que, durante o espetáculo, sejam utilizados recursos da linguagem cinematográfica, principalmente os relacionados com a edição como fusões de imagens, cortes e diferentes enquadramentos (panorâmica, plano médio, closes) criando dinamismo e movimento às imagens.

\section{Algumas considerações de quem trabalha na arte do Teatro de Sombras}

Ronaldo Robles e Sílvia Godoy9 (2012, p. 134) definem seu Teatro de Sombras como uma pesquisa contínua sobre a luz, assim como a pintura, a gravura, o cinema, a fotografia e as outras artes. Artistas como Abraham Palatnik, pioneiro na arte cinética no Brasil, "que explora efeitos visuais por meio de movimentos físicos e ilusão de ótica, utilizando pesquisa visual e rigor matemático em obras com instalações elétricas que criam movimentos e jogo de luzes"10, do mesmo modo, Regina Silveira, artista plástica, que em suas últimas obras "enfatiza a luz como significado central" 11, os dois artistas mostraram o poder plástico, conceitual e estético da luz, reflexo e sombra no universo das artes contemporâneas.

A Companhia Teatro Lumbra de Animação12 considera a iluminação o ponto chave da dramaturgia no Teatro de Sombras, e Alexandre Fávero ${ }^{13}$ (apud Oliveira, 2012, p. 152) alerta que um dos principais elementos do Teatro de Sombras é o escuro: "Quanto mais conscientes forem às manifestações de luz no espaço escuro, mais potencialidades terão as sombras e aquilo que surge delas". Rainer Reusch (2005, p.

9 Fundadores da Companhia Quase Cinema, de São Paulo, que há 10 anos pesquisa e trabalha com Teatro de Sombras.

10 Disponível em: http://madmag.com.br/2014/08/ultima-semana-pra-aproveitar-a-mostra-do-abraham-palatnik-no-mam/ - acesso em 20/09/2014.

11 Definição da própria autora Regina Silveira. Disponivel em: http://reginasilveira.com/\# - acesso em 20/09/2014
12 Companhia que há 15 anos estuda e trabalha especificamente com Teatro de Sombras, cujas pesquisas se direcionam para a dramaturgia da sombra. Fundador, diretor e integrante da Cia Teatro Lumbra de Animação. 
61), afirma que "sem luz, não há sombra. Isto tem um significado especial quando falamos de Teatro de Sombras". Com essas duas afirmações é visível que tanto o escuro como a luz são elementos que se completam e estão diretamente ligados, pois a sombra depende de ambos para se fazer presente. Entretanto, para que a sombra seja perceptível visualmente, a luz deve se inserir no escuro e ter um corpo/objeto/ silhueta que bloqueie seus raios luminosos.

A iluminação no Teatro de Sombras cria símbolos, signos, significados, partituras, subjetividades, intensidades, de um modo diferente da iluminação cênica. Segundo Fávero, a iluminação cênica pouco tem a ver com o Teatro de Sombras. Na iluminação cênica, o iluminador mostra ou oculta o que está diretamente em cena. No Teatro de Sombras é diferente, ele tem o trabalho de revelar as coisas numa outra dimensão, que não é mais a dimensão física do palco: "Para fazer a iluminação do Teatro de Sombras nós temos que ter um domínio tridimensional do espaço, só assim se conseguirá uma qualidade bidimensional de sombra" (Fávero apud Oliveira, 2011, p. 145).

É interessante pensar aqui no papel do iluminador e do ator-sombrista que cria e manipula a luz no seu trabalho. Fávero prefere o ator-animador operando a luz e interpretando com ela ao invés de ter um técnico na cabine de iluminação (vide figura 6). Ele considera que o trabalho do ator-animador e a iluminação são indissociáveis. Em seus espetáculos, por exemplo, toda a operação de luz é efetuada simultaneamente pelo ator-animador. Já conforme as pesquisas realizadas com grupos como Teatro Gioco Vita e Shattentheater, o Teatro de Sombras pode ser feito com o iluminador operando a luz de uma mesa, sendo que a escolha vai depender da poética utilizada nos seus espetáculos. Percebe-se, a partir dessas duas visões, as múltiplas oportunidades de práticas e experimentações.

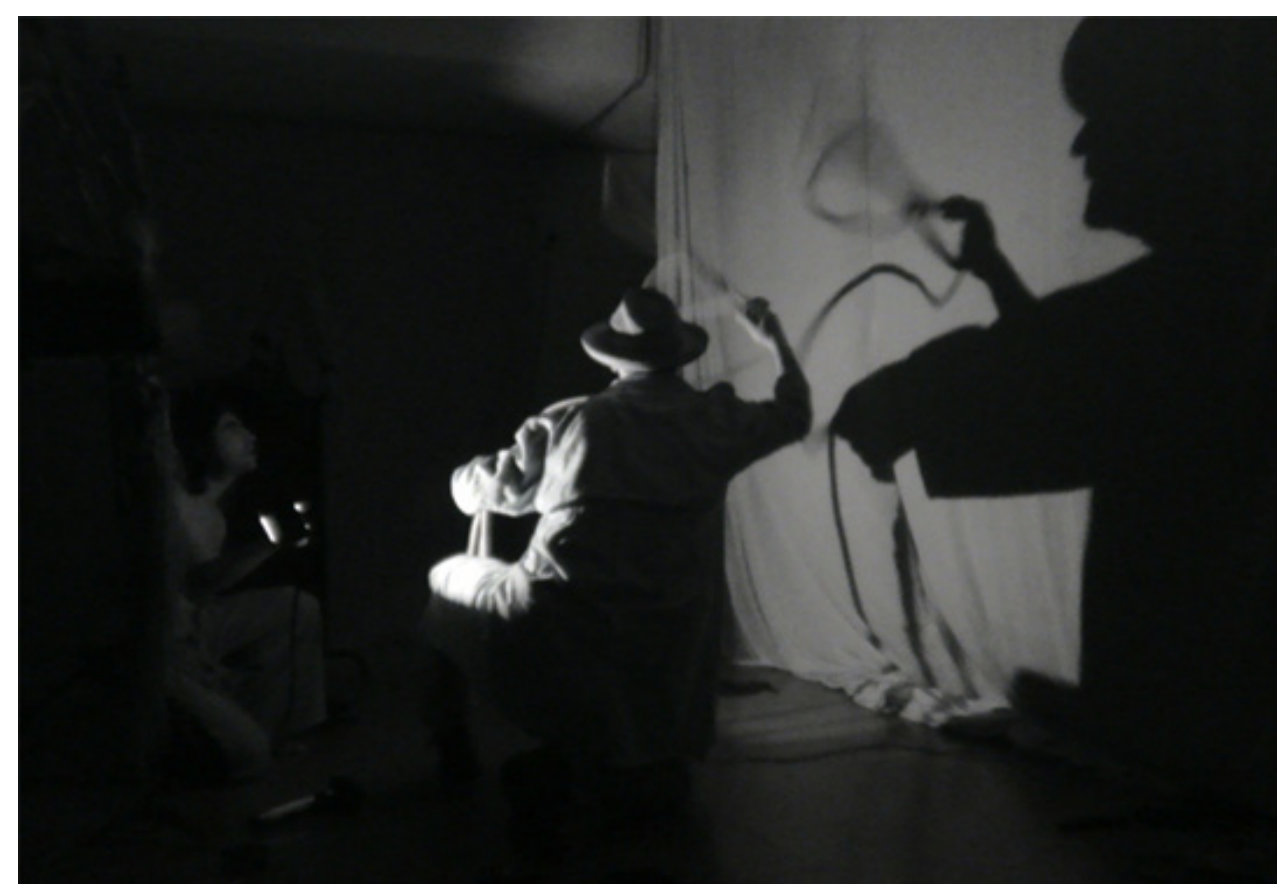

Figura 6 - Espetáculo Sacy Perere - a Lenda da Meia-noite, 2002. Acervo Cia Teatro Lumbra de Animação. 
No Teatro de Sombras a luz é primordial, pois sem ela a sombra fica ausente e o teatro não acontece. Com ela, ocorrem transformações artísticas para a projeção da sombra. Meschke, em 1985, já concluía que "devidamente utilizada, a luz é um recurso enorme, rico em possibilidades, mas também muito sensível. Tão rico é este instrumento que um raio de luz sozinho, procedente de uma única fonte, é capaz de dar a nossa matéria morta uma vida vertiginosa!"14 (1985, p. 87).

Considerando que existem concepções diferentes sobre o tipo de recurso para a produção das sombras, o que se nota é que cada artista faz a escolha das melhores técnicas para a criação dos seus espetáculos. Eles se portam como a personagem de História da Sombra, do escritor uruguaio Eduardo Galeano:

\footnotetext{
Naquela manhã, ele viu o que até então havia olhado sem ver: grudada a seus pés jazia a sombra, mais longa que seu corpo. Caminhou, correu. Onde ele ia, fosse onde fosse, a perseguidora sombra ia com ele. [...] Onde ele se perdia a sombra o encontrava. (2012, p. 17-18).
}

Esses artistas atuam como caçadores de sombras, não abrem mão de conhecer o funcionamento da luz e suas possibilidades porque para trabalhar com Teatro de Sombras, a curiosidade, a experimentação e o desejo de descobertas nunca se saturam. O que se percebe é uma constante luta para esconder o aparente e tornar visível o invisível, embora isso esteja quase sempre além do dizível.

\section{Referências}

ARNHEIM, Rudolf. Arte e Percepção Visual: Uma Psicologia da Visão Criadora. 10 edição. São Paulo: Pioneira, USP, 1996.

BELTRAME, Valmor. Teatro de Sombras, técnicas e linguagens: à guisa de apresentação. In: Móin-Móin: Revista de Estudos sobre o Teatro de Formas Animadas. Jaraguá do Sul: SCAR/UDESC, ano 8, v.9, 2012.

CASATI, Roberto. A Descoberta da Sombra: De Platão a Galileu, a história de um enigma que fascina a humanidade. São Paulo: Companhia das Letras, 2001.

CASTILLO, Domingo. Hágase La sombra! In: La sombra desvelada: um viaje por El teatro de sombras. 1ํㅡㄹ Edición. Zaragoza: Imprenta Provincial de Zaragoza, 2004.

FÁVERO, Alexandre. Dramaturgias da Sombra. In: Móin-Móin : Revista de Estudos sobre o Teatro de Formas Animadas. Jaraguá do Sul: SCAR/UDESC, ano 8, v.9, 2012.

\footnotetext{
14 "Debidamente utilizada, la luz es un recurso enorme, rico en posibilidades pero también muy sensible. !Tan rico es este instrumento que un solo rayo de luz, procedente de una única fuente, es capaz de dar a nuestra materia muerta una vida vertiginosa!" (tradução nossa).
} 
GALEANO, Eduardo. História da Sombra. In: Móin-Móin : Revista de Estudos sobre o Teatro de Formas Animadas. Jaraguá do Sul: SCAR/UDESC, ano 8, v.9, 2012.

HUMPRHEY, Jo. O Desafio em Preservar a Arte Dramática no Mundo de Hoje. Tradução: Anna Menk. In: Damianakos, Stathis. Théâtre D'ombres - Tradition et Modernite. Paris: l'Harmattan, 1986.

LONG, Robert. Tradição e tecnologia: o impacto da modernização no teatro de sombras javanês. Tradução de Anna Menk. In: DAMIANAKOS, Stathis. Théâtres D'Ombres. Paris: l'Harmattan, 1986.

LUCIANI, Nadia Moros. Sobre a performatividade da luz. In: O Mosaico. Revista de Pesquisa em Artes do Paraná. Curitiba, n. 8, p. 87-101, jul./dez., 2012.

LUO, Erica. Teatro de Sombras tradicional chinês. In: Móin-Móin : Revista de Estudos sobre o Teatro de Formas Animadas. Jaraguá do Sul: SCAR/UDESC, ano 8, v.9, 2012.

MARINA, Gonçalo. Entrevista a Ernesto Bechara: La Iluminacion in Primero Plan. In: Revista Umbra. Argentina: 2012. Disponível em: http://issuu.com/revistaumbra/docs/ numero2/13?e=5126525/1688404. Acesso em 10/08/2014.

MESCHKE, Michael. Una estética para ele Teatro de Títeres. Espanha: Instituto Ibero Americano, 1985.

OLIVEIRA, Fabiana Lazzari de. Alumbramentos de um corpo em Sombras: o ator na Companhia Teatro Lumbra de Animação. Dissertação (Mestrado), 2011. Centro de Artes, Universidade do Estado de Santa Catarina.

PAVIS, Patrice. Dicionário de Teatro. São Paulo: Perspectiva, 1999.

REUSCH, Rainer. Shadow Theatre: Theory + Practice. Germany: Internacionales Shattentheater Zentrum, 2005.

ROBLES, Ronaldo; GODOY Sílvia. Novos Caminhos do teatro de sombras: performance e work in progress. In: Móin-Móin : Revista de Estudos sobre o Teatro de Formas Animadas. Jaraguá do Sul: SCAR/UDESC, ano 8, v.9, 2012.

Recebido em: 3/09/2014 Aprovado em: 09/11/2014 